\title{
Impact of complications and comorbidities on treatment costs and health-related quality of life of patients with Parkinson's disease
}

\author{
Jan-Philipp Bach ${ }^{\text {a }}$, Oliver Riedel ${ }^{\mathrm{b}}$, Jens Klotsche ${ }^{\mathrm{b}}$, Annika Spottke ${ }^{\mathrm{c}}$, Richard Dodel ${ }^{\mathrm{a},{ }^{*} \text {, }}$ \\ Hans-Ulrich Wittchen ${ }^{\mathrm{b}}$ \\ a Philipps-University Marburg, Department of Neurology, Germany \\ b Technische Universität Dresden, Institute of Clinical Psychology and Psychotherapy, Germany \\ c Friedrich-Wilhelms-University Bonn, Department of Neurology, Germany
}

\begin{abstract}
Background: Data regarding both drug-related and non-drug-related costs in patients with Parkinson's disease (PD) are scarce, mainly due to the difficulties in data acquisition in experimental designs. Likewise, the reported impact of drug costs on total direct costs varies across different studies. In addition, the influence of comorbidities on both treatment costs and health-related quality of life has not been adequately evaluated.

Methods: A sample of office-based neurologists $(n=315)$ in Germany was asked to examine up to five consecutive patients with PD $(n=1449)$ on a specified day during the study period. Patients of all ages were eligible and their evaluation was performed using standardized questionnaires.

Results: PD-specific therapy costs increased with the stage of the disease, early onset of the disease and disease duration. The major costs were due to PD-related therapy, whereas other medications only resulted in minor costs. Disease stage mainly influenced direct therapy costs, with an observed increase of total daily costs from $€ 7.3$ to $€ 11.3 /$ day. In addition, disease onset at age $<65$ years resulted in total daily costs of $€ 11.2$ compared to late onset of disease ( $>75$ years) with daily therapy costs of $€ 5.3$. In this patient group neuropsychiatric comorbidities such as dementia and depression were only insufficiently treated. In addition, these comorbidities severely affected health-related quality of life.

Conclusion: Therapy costs were influenced by disease stage, disease onset as well as present comorbidities. Furthermore, comorbidities such as depression and dementia were diagnosed but were not adequately treated.
\end{abstract}

Keywords: PD treatment costs, Neuropsychiatric symptoms, EQ-5D, Depression, Dementia, Comorbidities

\section{Introduction}

During the past century life expectancy has substantially increased in industrialized nations. While this is certainly gratifying, the ongoing aging of our society means that age-related diseases will have an increasing economic impact on national healthcare systems. This is especially true for chronic neurodegenerative disorders such as Parkinson's disease (PD). PD affects 1 to 2 out of 100 people aged 65 years and nearly $10 \%$ of people older than 80 years 
[1]. Recent projections suggest that the number of individuals with PD over the age of 50 will probably double by the year 2030 [2,39]. Moreover, the course of illness in PD can be aggravated by motor complications, such as motor fluctuations and dyskinesias, and by a number of non-motor complications, including psychiatric comorbidities, gastrointestinal symptoms and sleep disorders, which require additional demanding intervention strategies $[3,4]$. All of these complications can have a considerable impact on the economic burden of the disease, especially through the requirements of additional and complex therapeutic interventions (e.g., for motor complications and depression, and deep brain stimulation), additional in-patient stays (e.g., for patients suffering hallucinations) or premature nursing home placement (e.g., psychosis) [5].

Although a number of studies have already evaluated the cost of illness in different countries [6], studies dealing with therapy costs in an office-based setting are relatively scarce and partly inconclusive [7]. Regarding the share of drug costs in the total cost, previous results from different studies varied from $20 \%$ in European investigations to up to more than $65 \%$ in a Chinese study [8]. Most reports suggest a strong association between the severity of PD and the expenses for disease-related medications, i.e., with disease progression, the drug costs increase by up to twice as much in advanced patients compared to patients in the early stages of the disease [9]. Similar associations have been found for motor complications, with their occurrence considerably increasing the cost of treating PD.

Although PD patients frequently develop non-motor comorbidities, which influence quality of life [10], the economic impact of concomitant dementia and behavioral and psychological symptoms in PD outpatients has not been systematically investigated to date. This study, which was based on an epidemiological survey involving office-based neurologists, focuses on the daily costs of PD treatment and the economic burden as well as the impact of nonmotor complications such as dementia and depression.

\section{Methods}

\subsection{Study design and recruitment procedure}

The study design and recruitment procedure of the German Study on the Epidemiology of Parkinson's Disease with Dementia (GEPAD) have previously been reported in detail $[11,12]$. Briefly, the primary goal of GEPAD was to estimate the prevalence of dementia and cognitive impairment among PD patients treated in the outpatient caresector. Data were derived from a random sample of PD outpatients $(\mathrm{n}=1449)$ who attended a representative sample of officebased neurologists $(n=315)$ in Germany on a specified day during the study period of September to October 2005. Patients of all ages and PD severity stages were eligible. Primary exclusion criteria were the patient's inability to read or write, severe cognitive impairment that precluded the application of the assessment or further logistical reasons preventing the examination (e.g., acute severe pain or medical emergencies).

Eligible PD patients visited the respective neurologists ( $\mathrm{n}=1749$ in total) on the study day; 300 patients were excluded from assessment by the physicians ( 89 for lack of consent, 39 for too severe impairment, 139 for logistical problems, and 33 for other reasons, for example language problems or sensory deficits). No clinical data were available for these patients. Thus, 1449 patients were included and examined according to the study protocol (overall participation rate: $82.3 \%$ ). All patients included fulfilled the NINDS criteria for possible PD [13]. Moreover, $n=873$ of these patients also met the UK Brain Bank criteria for PD [14]. As 
previously reported by Riedel et al., the subgroups of patients did not differ in terms of age $(\mathrm{p}=0.140)$, gender distribution $(\mathrm{p}=0.196)$ or the primary study outcome variables, as described in the next section (i.e. frequency of dementia $(p=0.761)$, MMSE score $(p=0.409)$ or MADRS score $(p=0.761))$ [15]. Therefore, we included the entire sample in the analysis of this paper. All PD patients were rated in the "on" stage. The local ethics committee reviewed and approved the study protocol (EK No. 140082005). Written informed consent was obtained from all participating patients or their caregivers.

\subsection{Study material}

Each patient was evaluated by the neurologist with a questionnaire that consisted of three parts. Part A documented sociodemographic information. Part B was related to the documented PD status, including the Hoehn and Yahr Scale (HY) [16] and the Unified Parkinson's Disease Rating Scale (UPDRS) [17]. Furthermore, the presence of neurological, neuropsychiatric or somatic symptoms was recorded. Each physician was also asked to list their patients' current intake of PD-related drugs as well as any other medication. All agents were recorded in terms of daily dosage. Part $C$ featured ratings of the cognitive level of functioning and depressive disorders. Cognitive impairment was assessed using the MiniMental State Examination (MMSE) and was rated as "none" (scores of 25-30), "mild" (2124), "moderate" (11-20) or "severe" (0-10) [18]. The diagnosis of dementia was based upon the corresponding DSM-IV criteria, using a structured symptom list [19,20]. Depression was screened with the Montgomery-Asberg Depression Rating Scale (MADRS), using a cut-off score of $\geq 14$ as an indicator of depressive symptoms [21]. Each patient was also administered the EQ-5D in order to assess their health-related quality of life [22].

\subsection{Drug cost calculation}

Daily therapy costs were calculated for each patient based on their documented medication. The dosage and dose per day were documented in the patients' questionnaire. Costs for prescription medications were obtained from the official German drug price list ("Rote Liste", 2006) and included a deduction according to the German social security code [23]. Only PDspecific drugs and drugs used to treat PD complications were included in the calculation. The costs were calculated in Euros $(€)$. The total costs (direct and indirect costs) were calculated from the statutory healthcare perspective.

\subsection{Statistical analyses}

Statistical analyses were performed using STATA Version 10.1 (StataCorp, 2008). The cost data are presented as median, arithmetic mean, standard deviation and 95\% confidence intervals of the mean. The median cost can be interpreted as the typical cost per patient while the mean cost multiplied by the number of patients describes the total cost. Cost data are usually highly skewed and standard, nonparametric or normalizing methods are often not appropriate [24]. The bootstrap technique provides an appropriate and flexible approach for presenting and comparing skewed cost data. Bootstrap confidence intervals of $95 \%$ were calculated using the bias-corrected and accelerated percentile method [25]. The number of bootstrap replications B was 1000. Univariate comparisons of cost differences between groups were estimated using a linear regression approach with standard errors estimated by bootstrapping that was defined by potential cost predictors. The total scores of the EQ-5D were calculated using the scoring algorithm for the German population [26]. Differences in predictor variables for quality of life were estimated using a linear regression approach with standard errors estimated by bootstrapping. 


\section{Results}

\subsection{Characterization of the study sample}

Table 1 provides an overview of the study sample. The mean age of the study population was $70.7 \pm 8.4$ years and about a third of the patients were female. The mean disease duration was $5.8 \pm 5.2$ years and, on average, disease onset had occurred when patients were aged $64.8 \pm 9.7$ years. In $50 \%$ of all patients, the age of PD onset occurred before the age of 66 , in $37.4 \%$ of patients between 66 and 75, and in $12.6 \%$ of patients after the age of 75 years. The majority of patients had been suffering from PD for up to 3 years $(41.4 \%)$, and 4 to 6 years $(22 \%)$. The disease duration for $36.6 \%$ of the patients had been longer than 7 years at the time of the study. The majority of patients were retired $(88 \%, \mathrm{n}=1250)$, in contrast to $5.5 \%$ who were still working; $13.1 \%$ claimed that retirement was due to PD and approximately $1 \%(n=11)$ of the patients were unemployed. Furthermore, $72.5 \%$ lived in a stable relationship while the remainder were single, widowed or divorced.

\subsection{Distribution of different PD medications within the study sample and the distribution of costs}

Table 2 shows the distribution of PD medications as stratified by the HY stage. It shows that $75.8 \%$ of patients received levodopa. Another $13.6 \%$ were receiving levodopa and a COMT inhibitor, so that more than $90 \%$ of the patients received levodopa.

Combined levodopa and COMT-inhibitor therapy was also frequently used and increased with advancing disease severity. Among the patients with severe cognitive impairment according to the MMSE $(n=3)$, all patients received dopamine agonists and levodopa, two were treated with antidepressants, one patient was treated with amantadine and one patient received a neuroleptic drug.

Overall, patients with dementia according to DSM-IV criteria received significantly less frequently dopamine agonists than non-demented patients $(55 \%$ vs. $71 \%, p<.001$, data not shown), whereas the slightly lower prescription rates in depressed vs. non-depressed patients according to the MADRS did not become significant $(63.2 \%$ vs. $67.5 \%, \mathrm{p}=.403)$.

Three patients were subcutaneously treated with apomorphine. Two patients were rated as HY stage III and one was rated as stage IV. None suffered from dementia and all were experiencing motor fluctuations. Daily treatment costs for these patients amounted to a mean of $€ 37.9$. When calculating the drug costs for the entire group, these patients were excluded as they would have considerably distorted the data of the other patients.

\subsection{Treatment patterns and costs due to psychiatric complications}

The drug costs stratified by drug group, comorbidity and disease stage are compiled in Table 3 . The main costs were due to PDrelated drugs $(\sim 86 \%)$; only minor costs were contributed by antidementia drugs $(4.6 \%)$, central nervous system (CNS) drugs $(2.3 \%)$ or other medications (7.0\%). Motor fluctuations, dyskinesias and advanced disease stage (HY stage/PD duration) significantly increased treatment costs. The presence of any of these led to a near doubling of both total and PD-associated daily costs. Young onset of disease was a cost-driving factor in 
this study, with significantly lower total costs occurring in patients with a disease onset after the age of 76 years (€5.3/day) in contrast to patients with a disease onset at $<65$ years $(€ 11.2)$.

Daily PD drug treatment costs decreased in patients with dementia or depression. Only 91 patients $(6.3 \%)$ received antidementia drugs, although 224 patients $(15.5 \%)$ suffered from cognitive impairment according to the MMSE $(\leq 24)$. The distribution of dementia drugs depending on the MMSE is shown in Table 3. The costs of antidementia drugs increased in univariate analyses according to age, disease stage and PD duration; however, the extent of cognitive impairment had a minor influence on costs. In the multivariate analyses, HY and PD duration were not significant predictors of costs, but age and cognitive impairment were.

Further analyses of drug consumption showed that some drugs which lack current evidence of efficacy for cognition deficits, such as gingko biloba and other nootropics, were found to be used by $2 \%$ of the total number of patients. These costs totalled approximately $€ 3.7 /$ day (median value) per patient.

Overall, 336 (25.2\%) patients suffered from depression (MADRS $\geq 14$ ). However, only 154 $(44.6 \%)$ of these patients received antidepressant medication. The total costs were $€ 3 /$ patient per day. The presence of depression led to a considerable increase in treatment costs for CNS medication. The CNS costs increased in patients who showed motor fluctuations and dyskinesias. Therapy costs of CNS drugs also increased with the HY stage as well as with the presence of dementia. Nevertheless, the total costs of these drugs were low compared to PD drug costs.

\subsection{Treatment patterns and costs of other non-motor complications}

Gastrointestinal comorbidities were noted in $9.9 \%$ of the patients. Gastrointestinal medications such as antacids, antiemetics and macrogol (polyethylene glycol, used in chronic obstipation) were used by our patient sample. However, their use was infrequent and only $1 \%$ of the patients received these medications. Macrogol, in particular, was taken by patients of advanced age and with HY stage V. The use of antacids was negligible as the majority of patients were not taking any.

Sleep disturbance was mentioned by $49 \%$ of the patients in our sample. However, drug consumption showed that only a minority of the patients received specific medication for this.

\subsection{Health-related quality of life in patients with PD}

The EQ-5D was analyzed based on HY stage, disease duration, motor fluctuations, dyskinesias and comorbidities (Table 4). The EQ-5D varied according to the HY stage, with a considerable reduction seen in the advanced stages of the disease. In patients with HY stage $\mathrm{V}$, the utility value dropped to 0.33 (lower scores indicate poorer quality of life). Age, disease duration and the occurrence of motor complications decreased health-related quality of life (HrQoL).

Comorbidities also influenced HrQoL. The patients who were suffering from cognitive impairment showed a decreasing utility value depending on whether the impairment was mild or moderate: patients with mild dementia did not experience much of a decrease in healthrelated quality of life (0.61) compared to patients without this cognitive impairment $(0.66)$. However, the progression of dementia to the moderate state led to a rapid decrease in the EQ$5 \mathrm{D}$ to a value of 0.48 . 
Moreover, anxiety, depression and hallucinations had a marked and significant influence on self-reported outcomes. An even greater effect on the EQ-5D values was seen when the presence of depression was further classified into mild, moderate or severe (data not shown). In the multivariate analyses with respect to psychiatric comorbidities, a major impact was found in patients suffering from depression, severe cognitive impairment and the occurrence of paranoid symptoms. The advent of hallucinations was not a predictive factor. Furthermore, gastrointestinal symptoms and advanced PD stage had a significant impact on HrQoL in PD patients.

\section{Discussion}

The present study is one of the first to evaluate treatment costs in a large and representative PD sample treated by office-based neurologists in Germany and taking non-motor symptoms and neuropsychiatric complications into account.

\subsection{Drug therapy and costs}

In the GEPAD study, therapy costs for PD increased from Hoehn and Yahr stages I to III, which reflects increasing disease complexity and demonstrates the need for combined therapy strategies in advanced stages of the disease, usually due to motor complications. Our data indicated a decrease in therapy costs in HY stages IV and V, as was also described by Dengler et al. [27]. According to Dengler, this change can be attributed to a switch in medication from expensive drugs in the early stages to levodopa in the later stages of the disease. In contrast, however, other studies described a continuing increase in therapy costs with advancing disease stage $[28,29]$.

The drug treatment of our older patients showed an inconsistent pattern regarding national recommendations [33]. More than $66 \%$ of all patients received dopamine agonists, which are actually indicated for patients younger than 70 years of age. However, only $48.6 \%$ of our patients belonged to this age group, therefore indicating a deviation from the recommendations for more than $17 \%$ of the patients. On the other hand, we observed an overall change in treatment strategy with increasing age in such a way that older patients were less likely to be treated with dopamine agonists, which is in agreement with the national recommendations.

We observed that COMT inhibitors were frequently used by our patient sample, which also complies with national recommendations, since $34 \%$ of all patients suffered from motor fluctuations [33]. In a comparable publication by Möller et al., the percentage of patients who used COMT inhibitors was $20.4 \%$, which is similar to the rate of use found in the present study [30].

Although behavioral and psychological symptoms have been reported to frequently occur in PD patients and have a considerable impact on the well-being and quality of life of these patients, the prescription of drugs in our study did not reflect this. In our cohort, $28.1 \%$ suffered from dementia, $25.2 \%$ suffered from clinically relevant depression and $11.5 \%$ suffered from hallucinations. Antidepressants were prescribed in $20.2 \%$ of the patients. However, antidementia drugs were only prescribed in $6.3 \%$ and $1.5 \%$, respectively, resulting in less than $7 \%$ of the total drug costs. This could partially reflect an often described difficulty in diagnosing depression in patients with PD as there is a substantial overlap between the 
symptoms of both disorders [34]. Therefore, it seems possible that depression might not be diagnosed on a regular basis in PD patients. This phenomenon was also described by Shulman et al. [35], who found that office neurologists failed to recognize the presence of depression and anxiety in $50 \%$ of the total cases. Interestingly, in our study, the diagnosis of depression was frequently made but treatment was not then initiated. However, we did not investigate the number of patients who were not diagnosed, and it is most likely that the number of depressive patients should have been higher, as seen in the study by Shulman et al. [35]. Another interpretation is that the clinician does not make a diagnosis of depression against a background of a severe underlying neurodegenerative disorder, despite increased MADRS scores. Furthermore, the provision of adequate therapy could be hampered by uncertainty over which drug to use as there are insufficient data regarding optimal antidepressive therapy. Only a few randomized controlled trials have tested the efficacy of antidepressants in patients with PD [36].

Another common neuropsychiatric feature is the occurrence of dementia with increasing disease duration. For patients with PD, there is evidence to show the use of cholinesterase inhibitors for this indication, and rivastigmine is licensed in Germany [37]. German guidelines state that the effect is generally modest, but it is significant in $15 \%$ of all patients treated $[33,38]$ and the treatment of patients with PD and mild to moderate dementia is recommended. However, there are side effects that need to be considered, such as a transient increase in tremor intensity during the initial dosing phase, as well as the common side effects of cholinesterase inhibitors. Our data showed that only $40 \%$ of the patients who suffered from moderate dementia received antidementia treatment. Further analyses are required in order to evaluate the prescription regime of patients with PD and dementia and to evaluate the reasons for the effects observed in our study.

In summary, there is a major gap between current recommendations and the treatment patterns in ambulatory care concerning the adequate handling of neuropsychiatric complications in PD. Further studies are necessary in order to identify obstacles and provide adequate treatment of neuropsychiatric complications as these comorbidities - as already mentioned above - are major contributors to the quality of life of these patients.

\subsection{Health-related quality of life}

There is evidence to show that the choice of antiparkinsonian medication may affect HrQoL. In a recent article, 14 double-blind, placebo-controlled trials were assessed [31]. Several positive results for both COMT inhibitors and dopamine agonists were shown, but the results were ambiguous. A trial by Noyes compared the impact of pramipexole and levodopa on different domains of HrQoL. They showed that the dopamine agonist supported non-motorsymptom-associated improvements, whereas levodopa improved HrQoL by a direct influence on motor symptoms. However, another study by Stocchi et al. examined the effect of levodopa with and without a COMT inhibitor with respect to the development of dyskinesias [32]. In a sample of more than 700 patients they found that combination therapy using COMT inhibitors did not delay the time of onset of dyskinesias compared to standard levodopa treatment. In contrast, combination therapy decreased the time to dyskinesias compared to levodopa treatment alone.

Regarding neuropsychiatric comorbidities, we found a significant reduction in the HrQoL with increasing disease severity. The presence of dementia was both negatively correlated with, and influenced by, the presence of depression [31]. Therefore, adequate treatment is mandatory when patient-reported outcomes are important in the treatment of PD patients. 


\subsection{Limitations}

This study has several limitations. Only office-based neurologists were included and thus the impact of patients treated in other levels of the healthcare system was neglected in this study. However, it was our primary aim to evaluate therapy costs in an office-based setting as this is how the majority of PD patients are treated in Germany. Asking neurologists to include patients in the study on a pre-specified day may have introduced the possibility of a bias. Therefore, the patient distribution must be interpreted with caution as this was not a community survey but a survey based on office-based neurologists. Furthermore, PD patients at earlier stages of the disease might initially be seen by their general practitioner rather than an office-based neurologist, thus their participation may have been underestimated in this study.

Another important limitation refers to the calculation of therapy costs, which we restricted to the medications presented in this paper (i.e. anti-Parkinson medications and other CNS medications). We did not collect data on the costs of over-the-counter medications, which are also frequently used by PD patients. In addition, the cost estimates would have been higher if specialized PD centers and hospitals were included, since severe and difficult-to-treat cases are usually referred to these centers. It should also be noted that prior to the study assessment 39 patients were excluded from the study by their physicians due to a degree of impairment that was too severe. Therefore, we lack further information regarding the clinical status and therapy expenses of these patients, whose higher level of comorbidity would have presumably resulted in higher costs compared to the patients who were included. Finally, although the patients were evaluated in the "on" state, we could not be sure that these patients were receiving the "best medical treatment". This may have introduced a bias in the evaluation of patient-reported outcomes.

\begin{tabular}{|c|c|}
\hline Variable & Value \\
\hline \multicolumn{2}{|l|}{ Sociodemographics } \\
\hline Male, $N(x)$ & 877 (6as) \\
\hline Female, $N(x)$ & 572 (39.5) \\
\hline Age, yeurs (ment \pm sd) & $707 \pm 84$ \\
\hline \multicolumn{2}{|l|}{ Marital staus, $\mathrm{N}(\boldsymbol{x})^{\mathrm{A}}$} \\
\hline Married & $1049(725)$ \\
\hline Widorwed & 269 (18.6) \\
\hline Single & $65(45)$ \\
\hline Divarced & $64(44)$ \\
\hline \multicolumn{2}{|l|}{ Occupational status, $\mathrm{N}\left(x^{\mathrm{b}}\right.$} \\
\hline Retired (total) & $1250(880)$ \\
\hline Hamemaker & $81(5.7)$ \\
\hline Employed & $78(5.5)$ \\
\hline Unemployed & $11(08)$ \\
\hline \multicolumn{2}{|l|}{ Clinical dharacteristics } \\
\hline \multicolumn{2}{|l|}{ Hoehn \& Yahr stage, $\mathrm{N}(x)^{c}$} \\
\hline Stage 1+1I & $617(442)$ \\
\hline Stage III & $540(387)$ \\
\hline Stages $N+V$ & $239(17.1)$ \\
\hline Age of PD onset years (mean $\pm \mathrm{sd}$ ) & $648 \pm 97$ \\
\hline PD duration years (mean $\pm s d$ ) & $58 \pm 5.2$ \\
\hline Dys kinesiax, $N(x)$ & $394(21.5)$ \\
\hline Motor fluctuations, $\mathrm{N}(x)$ & 494 (349) \\
\hline Gastroin zstinal diseaser, $N(x)^{d}$ & 141 (99) \\
\hline \multicolumn{2}{|l|}{ Neuropsychiatric characteristics } \\
\hline Depression (MADRS $\geq 14), N(x)$ & $336(25.2)$ \\
\hline Dementia (DSM-N criteria), N $(x)$ & $407(281)$ \\
\hline Cognitive impuirment (MMSE: 242$), \mathrm{N}(x)$ & $224(15,5)$ \\
\hline Hallucinations, $N(\mathscr{x})$ & 166 (11.5) \\
\hline Delusions. $N(\mathscr{x})$ & $32(22)$ \\
\hline
\end{tabular}




\begin{tabular}{|c|c|c|c|c|c|c|c|c|c|c|c|c|c|c|c|c|c|c|}
\hline & \multirow{2}{*}{\multicolumn{2}{|c|}{ Total }} & \multicolumn{6}{|c|}{ Disease status by Hoehn and Yahr" } & \multicolumn{6}{|c|}{ Cognitive impsirment (MMSE-scare) } & \multicolumn{4}{|c|}{ Depression (MAD RS score) } \\
\hline & & & \multirow{2}{*}{\multicolumn{2}{|c|}{$\begin{array}{l}\overline{1+I I} \\
\bar{N}=617\end{array}$}} & \multirow{2}{*}{\multicolumn{2}{|c|}{$\begin{array}{l}\text { III } \\
\text { N=540 }\end{array}$}} & \multirow{2}{*}{\multicolumn{2}{|c|}{$\begin{array}{l}\mathrm{N}+\mathrm{V} \\
\mathrm{N}=239\end{array}$}} & \multirow{2}{*}{\multicolumn{2}{|c|}{$\begin{array}{l}\text { Nane } \\
(30-25) \\
N=1068\end{array}$}} & \multirow{2}{*}{\multicolumn{2}{|c|}{$\begin{array}{l}\begin{array}{l}\text { Mild } \\
(21-24)\end{array} \\
\mathrm{N}=130\end{array}$}} & \multirow{2}{*}{\multicolumn{2}{|c|}{$\begin{array}{l}\begin{array}{l}\text { Moderate } \\
(20-11)\end{array} \\
N=63\end{array}$}} & \multirow{2}{*}{\multicolumn{2}{|c|}{$\begin{array}{l}\text { No }(s 13) \\
N=1036\end{array}$}} & \multirow{2}{*}{\multicolumn{2}{|c|}{$\begin{array}{l}\text { Yes }(\geq 14) \\
N=345\end{array}$}} \\
\hline & \multicolumn{2}{|c|}{$\mathrm{N}=1449$} & & & & & & & & & & & & & & & & \\
\hline & $\bar{N}$ & $\underline{x}$ & $\bar{N}$ & $x$ & $\bar{N}$ & $\mathscr{x}$ & $\bar{N}$ & $x$ & $\mathrm{~N}$ & $x$ & $\bar{N}$ & $x$ & $\bar{N}$ & $x$ & $\mathrm{~N}$ & $x$ & $\mathrm{~N}$ & $\underline{x}$ \\
\hline No medication/no response & 62 & 43 & 25 & 41 & 19 & 35 & 12 & 5.0 & 42 & 39 & 2 & 1.5 & 3 & 48 & 46 & 44 & 13 & 3.8 \\
\hline Amuladine & 417 & 288 & 139 & 225 & 192 & 35.6 & $\Leftrightarrow$ & 289 & 335 & 31.4 & 37 & 285 & 14 & 222 & 305 & 294 & 89 & 258 \\
\hline Anticholinergics & 66 & 46 & 26 & 42 & 25 & 46 & 12 & 5.0 & 47 & 44 & 9 & 69 & 1 & 1.6 & 42 & 41 & 21 & 61 \\
\hline Antiemetics & 8 & a. & 1 & $a_{2}$ & 7 & 1.3 & 0 & ao & 6 & a.6 & 2 & 1.5 & 0 & ao & 5 & as & 2 & a.6 \\
\hline Apomorp hine & 3 & 02 & 0 & ao & 2 & 0.4 & 1 & $a_{4}$ & 3 & a.3 & 0 & ao & 0 & ao & 3 & $a_{3}$ & 0 & ao \\
\hline Benmodinsepine & 4 & 0.3 & 1 & $a_{2}$ & 0 & ao & 3 & 13 & 2 & 0.2 & 0 & ao & 0 & ao & 2 & 0.2 & 2 & 0.6 \\
\hline Betablockers & 5 & 0.4 & 2 & $a_{3}$ & 2 & 0.4 & 1 & $0_{4}$ & 3 & $a_{3}$ & 2 & 1.5 & 0 & ao & 4 & $a_{4}$ & 1 & 0.3 \\
\hline Budipine & 14 & 10 & 7 & 1.1 & 6 & 1.1 & 0 & ao & 9 & as & 3 & 23 & 0 & ao & 8 & as & 4 & 1.2 \\
\hline COMI inhibitar & 154 & 106 & 27 & 44 & 80 & 148 & 42 & 17.6 & 105 & 98 & 20 & 15.4 & 8 & 127 & 102 & 99 & 42 & 122 \\
\hline Dopaminagonists & 964 & 66.5 & 402 & 652 & 372 & 689 & 157 & 65.7 & 741 & 69.4 & 80 & 61.5 & 33 & 524 & 699 & 67.5 & 218 & 63.2 \\
\hline Rxsyiline & 13 & 0.9 & 4 & a.7 & 7 & 1.3 & 2 & as & 10 & a9 & 2 & 15 & 0 & ao & 9 & 09 & 4 & 1.2 \\
\hline Selegiline & 117 & 81 & 58 & 9.4 & 44 & 82 & 14 & 59 & 91 & 8.5 & 10 & 7.7 & 4 & 6.4 & 90 & 87 & 22 & 6.4 \\
\hline Other & 4 & 0.3 & 1 & 02 & 1 & $a_{2}$ & 2 & as & 3 & 0.3 & 0 & ao & 1 & 1.6 & 1 & a.1 & 3 & as \\
\hline L-Dopa alane & 126 & 87 & 71 & 115 & 42 & 7.8 & 9 & 38 & 95 & 89 & 8 & 6.2 & 5 & 79 & 107 & 103 & 11 & 32 \\
\hline Dopamine aganists alon & 88 & 61 & 76 & 123 & 5 & a9 & 4 & 1.7 & 69 & 6.5 & 3 & 23 & 0 & ao & 80 & 7.7 & 6 & 1.7 \\
\hline L-Dopp and dopumine agonists & 228 & 153 & 111 & 180 & 80 & 148 & 28 & 11.7 & 175 & 164 & 20 & 15.4 & 6 & as & 182 & 17.6 & 33 & 96 \\
\hline
\end{tabular}

Table 3

Distribution of drug treatrment costs (e) for Parkinson's disense, dementis, other ONS disease and other medicabon in the GEPAD tral sample (pabents an apomarphine treatment were exd uded).

\begin{tabular}{|c|c|c|c|c|c|c|c|c|c|c|c|c|c|c|c|c|}
\hline & & \multicolumn{3}{|l|}{ Total costs } & \multicolumn{3}{|l|}{ PD costs } & \multicolumn{3}{|c|}{ Demertia costs } & \multicolumn{3}{|l|}{ CNS ast } & \multicolumn{3}{|c|}{ Other medication costs } \\
\hline & & $\overline{M \pm s d}$ & $95 x 0$ & $\mathrm{p}$ & $\overline{M \pm s d}$ & $95 x a$ & $\mathrm{p}$ & $\overline{M \pm s d}$ & $95 x 0$ & $\mathrm{p}$ & $\overline{M_{ \pm} s d}$ & $95 x 0$ & $\mathrm{p}$ & $\overline{M_{ \pm} s d}$ & $95 x \mathrm{Cl}$ & $\mathrm{p}$ \\
\hline \multirow{4}{*}{$\begin{array}{l}\text { Total } \\
\text { Hoehn \& Yahr stage }\end{array}$} & & $87 \pm 124$ & $82-96$ & - & $75+63$ & $7.2-7.9$ & & $0.4+66$ & $02-1.2$ & - & $02 \pm 1.0$ & $02-03$ & & $06 \pm 81$ & $0 A-16$ & \\
\hline & $1+11$ & $7.3 \pm 11.6$ & $67-87$ & (Ref) & $6.5 \pm 6.1$ & $60-7.0$ & (Ref) & $0,5 \pm 100$ & a.1-22 & (Ref) & $0.1 \pm 0.5$ & a.1-02 & (Ref) & $02 \pm 07$ & $02-0.3$ & (Ref) \\
\hline & & $93 \pm 141$ & 86-116 & & $81 \pm 69$ & $7.7-89$ & & $02 \pm 08$ & a.1-03 & $\mathrm{ns}$ & $02 \pm 09$ & $02-04$ & & $08 \pm 124$ & $02-35$ & \\
\hline & $\mathrm{IV}+\mathrm{V}$ & $11.3 \pm 104$ & $101-128$ & - & $89 \pm 73$ & $81-99$ & - & $05 \pm 12$ & a.3-a7 & $\mathrm{ns}$ & $0.5 \pm 1.7$ & 0408 & - & $14 \pm 72$ & $0.7-27$ & - \\
\hline \multirow[t]{4}{*}{ Cognitive impairment" } & Nane & $88 \pm 103$ & $84-97$ & ( $\mathrm{Ref}$ ) & $79 \pm 6.3$ & $7.6-8.5$ & (Ref) & $03 \pm 73$ & a.1-1.5 & (Ref) & $02 \pm 1.0$ & $02-03$ & (Ref) & $04 \pm 20$ & $03-0.5$ & (Ref) \\
\hline & Mild & $94 \pm 255$ & 69-18.1 & $n=$ & $63 \pm 55$ & $54-7.3$ & & $a s \pm 13$ & a4-08 & ns & $02 \pm 0.5$ & $a_{1}-a_{3}$ & ns. & $24 \pm 249$ & $02-133$ & $\mathrm{~ns}$ \\
\hline & Moderate & $81 \pm 63$ & $66-99$ & $\mathrm{~ns}$ & $59 \pm 5.5$ & $46-7.4$ & • & $1.4 \pm 20$ & $09-20$ & & $0.5 \pm 1.1$ & a3-09 & & $0.3 \pm 0.6$ & $0.1-0.5$ & $\mathrm{~ns}$ \\
\hline & Severe & $82 \pm 39$ & 49-10.7 & n.s. & $73 \pm 3.7$ & 51-11.5 & ns. & $0 \& \pm 10$ & a0-1.1 & $\mathrm{ns}$ & $03 \pm 0.5$ & a.3-09 & ns. & $00 \pm \infty$ & - & \\
\hline \multirow[t]{2}{*}{ Dementis (DSM-N) } & No & $93 \pm 139$ & 87-105 & (Ref) & $81 \pm 69$ & $7.8-87$ & (Ref) & $03 \pm 78$ & $00-13$ & (Ref) & $0.2 \pm 1.0$ & a1-a3 & (Ref) & $07 \pm 94$ & $0 A-1.7$ & (Ref) \\
\hline & Yes & $73 \pm 73$ & $66-80$ & & $59 \pm 58$ & $54-65$ & & $06 \pm 1.4$ & as-as & ns & $03 \pm 08$ & $03-04$ & & $04 \pm 34$ & $02-12$ & $\mathrm{~ns}$ \\
\hline \multirow[t]{3}{*}{ Age of PD anset (years) } & $\leq 65$ & $11.2 \pm 133$ & 106-13.1 & (Ref) & $101+73$ & $97-11.0$ & (Bef) & $a 1+0$, & $a_{1-02}$ & (Ref) & $a 2 \pm 1.0$ & $02-04$ & (Bef) & $08+11.2$ & $03-29$ & (Ref) \\
\hline & $66-75$ & $64 \pm 68$ & $58-7.1$ & & $53 \pm 49$ & $49-58$ & & $0.2 \pm 03$ & a1-a3 & $\mathrm{ns}$ & $0.2 \pm 09$ & $02-04$ & ns. & $06 \pm 43$ & $03-13$ & $\mathrm{~ns}$ \\
\hline & $\geq 76$ & $53 \pm 194$ & $37-118$ & $n=$ & $29 \pm 34$ & $25-35$ & - & $20 \pm 191$ & 0482 & 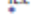 & $a_{1} \pm 0_{3}$ & a1-a1 & . & $03 \pm 08$ & $02-04$ & 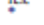 \\
\hline \multirow[t]{3}{*}{ PD duration (years) } & $\leq 3$ & $5.6 \pm 5.9$ & $52-62$ & (Ref) & $49+50$ & $45-5.4$ & (Bef) & $02 \pm 08$ & $a_{1-03}$ & (Ref) & $02 \pm 1.2$ & $01-04$ & (Ref) & $04+28$ & $02-10$ & (Ref) \\
\hline & $4-6$ & $92 \pm 67$ & $85-100$ & & $86 \pm 66$ & $79-94$ & & $02+03$ & a1-03 & ns & $02 \pm 05$ & a1-02 & $\begin{array}{l}\text { ns. } \\
\text { ns. }\end{array}$ & $0.3+1.1$ & $02-0.5$ & $\mathrm{~ns}$ \\
\hline & $\geq 7$ & $11.8+187$ & $108-144$ & - & $97+7 \mathrm{~A}$ & $92-106$ & - & $a 7+112$ & $02-32$ & 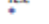 & $a 3+a 7$ & $02-03$ & ns. & $11+134$ & $04-47$ & $\infty$ \\
\hline \multirow[t]{2}{*}{ Mobr fluctuteons } & No & & $64-7.8$ & (Ref) & $58 \pm 5.4$ & $55-62$ & (Ref) & as $=$ & $02-1.6$ & (Ref) & $02 \pm 0.8$ & $02-03$ & (Bef) & $04 \pm 28$ & $03-07$ & (Ref) \\
\hline & $\begin{array}{l}\text { No } \\
\text { Yes }\end{array}$ & $\begin{array}{l}69 \pm 102 \\
121 \pm 153\end{array}$ & $11.4-146$ & (ke-1) & $\begin{array}{r}38 \pm 3 A \\
104 \pm 7 A\end{array}$ & 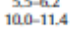 & (jet) & $\begin{array}{l}0.5 \pm 83 \\
0.3 \pm 0.9\end{array}$ & a.2-0. & $\begin{array}{l}\text { (Ret) } \\
\text { ns }\end{array}$ & $\begin{array}{l}0 . \pm 0.8 \\
03 \pm 1.2\end{array}$ & $02-05$ & (let) & $\begin{array}{l}04 \pm 28 \\
1.1 \pm 134\end{array}$ & 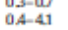 & 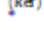 \\
\hline \multirow[t]{2}{*}{ Dyskinesias } & No & $\begin{array}{l}2.7 \pm 130 \\
7.7 \pm 130\end{array}$ & $7.1-9.1$ & (Ref) & $\begin{array}{l}65 \pm 60 \\
65 \pm 17\end{array}$ & $6.1-6.8$ & (Ref) & $04 \pm 75$ & $02-1.3$ & (Ref) & $02 \pm 0.8$ & $02-02$ & (Ref) & $\begin{array}{l}1.134 \\
0.9 \pm 89\end{array}$ & $03-1,7$ & (Ref) \\
\hline & Yes & $125 \pm 93$ & $11.8-14.1$ & & $11.0 \pm 76$ & $105-123$ & & $03 \pm 10$ & $02-04$ & ns & $04 \pm 1.4$ & $a 3-a 7$ & & $08 \pm 52$ & $0 A-16$ & $\mathrm{~ns}$ \\
\hline \multirow{2}{*}{ Sleqp distarhunes } & No & $81 \pm 127$ & $7.4-9.4$ & (Ref) & $68 \pm 62$ & $64-7.3$ & (Ref) & $02 \pm 0.9$ & $02-03$ & (Ref) & 02 . & $a_{1}-a_{3}$ & (Ref) & $09 \pm 11.1$ & $0 .-25$ & (Ref) \\
\hline & Yes & $90 \pm 79$ & 86-9 & n.s. & $81 \pm 7.1$ & $7.8-89$ & & $02 \pm 08$ & a1-a3 & $\mathrm{ns}$ & $03=$ & $02-04$ & & $04 \pm 28$ & 03-0.9 & ns \\
\hline \multirow{2}{*}{ Depression ${ }^{b}$} & No & $83 \pm 7$ & 79. & (Ref) & 7.6土 & $73-82$ & (Bef) & $a_{2} \pm$ & $a_{1}-a_{2}$ & (Ref) & $a_{1}$ & $a_{1}-a_{2}$ & (Ref) & $04 \pm$ & $03-06$ & (Ref) \\
\hline & Yes & $95 \pm 21.4$ & $7.8-130$ & n.s. & $6.6 \pm 58$ & $60-73$ & & $1.1 \pm 135$ & $03-42$ & & $05 \pm 1.5$ & 040.8 & & $13 \pm 157$ & $03-52$ & $\mathrm{~ns}$ \\
\hline
\end{tabular}

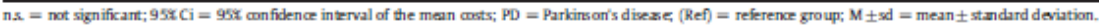

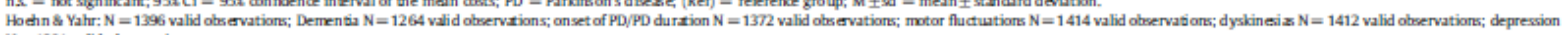
$\mathrm{N}=1381$ valid observations.

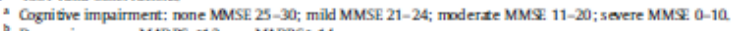

- Depressiant: nane MADRS $\leq 13 ;$ yes MaDRS $\geq 14$. 


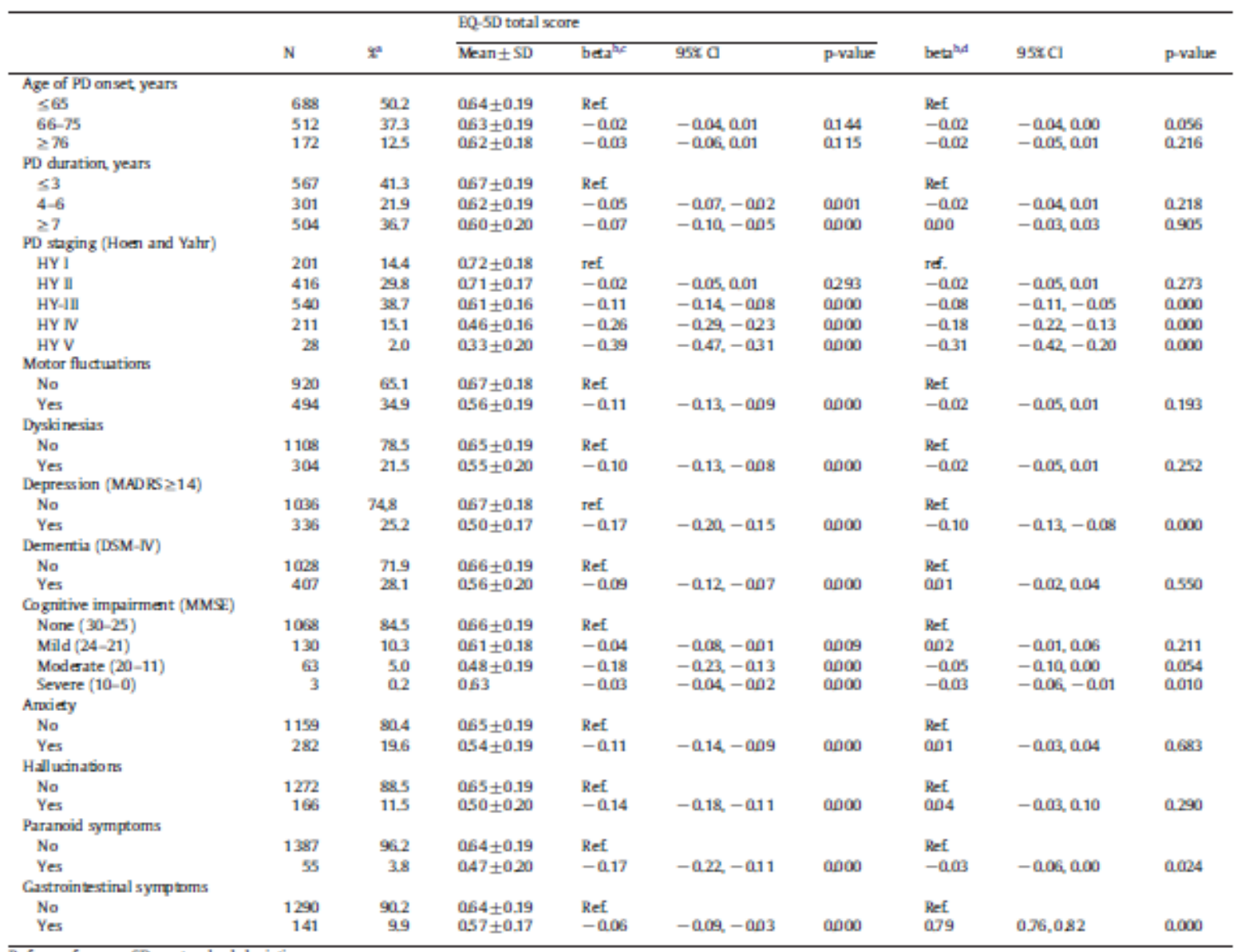

a All percentages refer $m$ number of subjects with ocisting data.

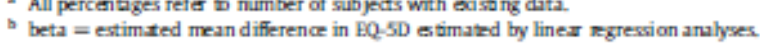

"beta = extimited me

a Mul tivariat anal ges.

\section{Conflict of interest}

All authors declare that there is no conflict of interest regarding the content of this article.

\section{Acknowledgments}

The GEPAD study was supported by an unrestricted educational grant from Novartis Pharma $\mathrm{GmbH}$.

\section{References}

[1] von Campenhausen S, Bornschein B, Wick R, Bötzel K, Sampaio C, Poewe W, et al. Prevalence and incidence of Parkinson's disease in Europe. Eur J Neuropsychopharmacol 2005;15:473-90.

[2] Dorsey ER, Constantinescu R, Thompson JP, Biglan KM, Holloway RG, Kieburtz K, et al. Projected number of people with Parkinson disease in the most populous nations, 2005 through 2030. Neurology 2007;68(5):384-6.

[3] Martikainen KK, Luukkaala TH, Marttila RJ. Parkinson's disease and working capacity. Mov Disord 2006;21(12):2187-91. 
[4] Schrag A, Banks P. Time of loss of employment in Parkinson's disease. Mov Disord 2006;21(11):1839-43.

[5] Goetz CG, Stebbins GT. Risk factors for nursing home placement in advanced Parkinson's disease. Neurology 1993;43(11):2227-9.

[6] von Campenhausen S, Winter Y, Rodrigues e Silva A, Sampaio C, Ruzicka E, Barone P, et al. Cost of ilness and care in Parkinson's disease: An evaluation in six countries. European Neuropsychopharmacology 2011;21(2):180-91.

[7] Ehret R, Balzer-Geldsetzer M, Reese JP, Dodel I, Becker E, Christopher A, et al. Direct costs for Parkinson's treatment in private neurology practices in Berlin. Nervenarzt 2009;80(4):452-8.

[8] Wang G, Cheng Q, Zheng R, Tan Y-Y, Sun X-K, Zhou H-Y, et al. Economic burden or Parkinson's disease in a developing country: a retrospective cost analysis in Shanghai, China. Mov Disord 2006;21(9):1439-43.

[9] Keller S, Kessler T, Meuser T, Bremen D, Jost WH. Analyse der direkten Kosten in der Parkinson-Therapie. Nervenarzt 2003;74:1105-9.

[10] Schrag A. Quality of life and depression in Parkinson's disease. J Neurol Sci 2006;248(1-2):151-7.

[11] Riedel O, Heuser I, Klotsche J, Dodel R, Wittchen HU. Occurrence risk and structure of depression in Parkinson disease with and without dementia: results from the GEPAD study. J Geriatr Psychiatry Neurol 2010;23(1):27-34.

[12] Riedel O, Klotsche J, Spottke A, Deuschl G, Forstl H, Henn F, et al. Cognitive impairment in 873 patients with idiopathic Parkinson's disease. Results from the German Study on Epidemiology of Parkinson's Disease with Dementia (GEPAD). J Neurol 2008;255(2):255-64.

[13] Gelb DJ, Oliver E, Gilman S. Diagnostic criteria for Parkinson disease. Arch Neurol 1999;56(1):33-9.

[14] Hughes AJ, Daniel SE, Kilford L, Lees AJ. Accuracy of clinical diagnosis of idiopathic

Parkinson's disease: a clinico-pathological study of 100 cases. J Neurol Neurosurg Psychiatry 1992;55(3):181-4.

[15] Riedel O, Klotsche J, Spottke A, Deuschl G, Forstl H, Henn F, et al. Frequency of dementia, depression, and other neuropsychiatric symptoms in 1449 outpatients with Parkinson's disease. J Neurol 2010;257(7):1073-82.

[16] Hoehn M, Yahr M. Parkinsonism: onset, progression and mortality. Neurology 1967; 17:427-42.

[17] Fahn S. Unified Parkinson's disease rating scale. In: Fahn S, Calne D, editors. Recent developments in Parkinson's disease. Florham Park, NJ: MacMillan Healthcare Information; 1987. p. 153-63.

[18] Folstein M, Folstein S, McHugh P. Mini-mental state: a practical method for grading the mental state of patients by the clinician. J Psychiatr Res 1975;12:189-98.

[19] American Psychiatric Association. Diagnostic and Statistical Manual of Mental Disorders - Text revision. 4 ed. Washington, DC: American Psychiatric Association 2000 [20] Zaudig M, Hiller W, Geiselmann B, Hansert E, Linder G, Mombour W, et al. SIDAM Strukturiertes Interview für die Diagnose einer Demenz vom Alzheimer Typ, der Multiinfarkt- (oder vaskulären) Demenz und Demnzen anderer Ätiologien nach DSM-III-R, DSM-IV und ICD-10. Göttingen: Hogrefe; 1996.

[21] Montgomery S, Asberg M. A new depression scale, designed to be sensitive to change. Br J Psychiatry 1979;134:382-9.

[22] Group EuroQuol. EuroQuol: a new facility for the measurement of health-related quality of life. Health Policy 1990;16:199-208.

[23] Bundesverband der pharmazeutischen Industrie. Rote Liste. Weinheim: Rote Liste Verlag 2009. 
[24] Barber JA, Thompson SG. Analysis of cost data in randomized trials: an application of the non-parametric bootstrap. Stat Med 2000;19(23):3219-36.

[25] Desgagne A, Castilloux AM, Angers JF, LeLorier J. The use of the bootstrap statistical method for the pharmacoeconomic cost analysis of skewed data. Pharmacoeconomics 1998;13(5):487-97.

[26] Greiner W, Weijnen T, Nieuwenhuizen M, Oppe S, Badia X, Busschbach J, et al. A single European currency for EQ-5D health states. Results from a six-country study. Eur J Health Econ 2003;4(3):222-31.

[27] Dengler I, Leukel N, Meuser T, Jost WH. Prospective study of the direct and indirect costs of idiopathic Parkinson's disease. Nervenarzt 2006;77(10):1204-9.

[28] Lindgren P, Campenhausen S, Spottke A, Siebert U, Dodel R. Cost of Parkinson's disease in Europe. Eur J Neurol 2005;12(Suppl. 1):68-73.

[29] Dodel RC, Singer M, Kohne-Volland R, Szucs T, Rathay B, Scholz E, et al. The economic impact of Parkinson's disease. An estimation based on a 3-month prospective analysis. Pharmacoeconomics 1998;14(3):299-312.

[30] Möller J, Körner Y, Dodel R, Meinsdorfner C, Stiasny-Kolster K, Spottke A, et al. Pharmacotherapy of Parkinson's disease in Germany. J Neurol 2005;252:926-35.

[31] Gallagher DA, Schrag A. Impact of newer pharmacological treatments on quality of life in patients with Parkinson's disease. CNS Drugs 2008;22(7):563-86.

[32] Stocchi F, Rascol O, Kieburtz K, Poewe W, Jankovic J, Tolosa E, et al. Initiating levodopa/carbidopa therapy with and without entacapone in early Parkinson disease: the STRIDE-PD study. Ann Neurol 2010;68(1):18-27.

[33] Eggert KM, Oertel WH, Reichmann H, Arnold G, Baas H, Berg D, et al. ParkinsonSyndrome: Diagnostik und Therapie. In: Diener H, Putzki N, editors. Leitlinien für die Diagnostik und Therapie in der Neurologie. Stuttgart: Georg Thieme Verlag; 2008.

[34] Storch A, Ebersbach G, Fuchs G, Jost WH, Odin P, Reifschneider G, et al. Depression in Parkinson's disease. Part 1: epidemiology, signs and symptoms, pathophysiology and diagnosis. Fortschr Neurol Psychiatr 2008;76(12):715-24.

[35] Shulman LM, Taback RL, Rabinstein AA, Weiner WJ. Non-recognition of depression and other non-motor symptoms in Parkinson's disease. Parkinsonism Relat Disord 2002;8(3):193-7.

[36] Weintraub D, Morales KH, Moberg PJ, Bilker WB, Balderston C, Duda JE, et al. Antidepressant studies in Parkinson's disease: a review and meta-analysis. Mov Disord 2005;20(9):1161-9.

[37] Poewe W, Gauthier S, Aarsland D, Leverenz JB, Barone P, Weintraub D, et al. Diagnosis and management of Parkinson's disease dementia. Int J Clin Pract 2008;62(10):1581-7. [38] Deuschl G, Maier W. S3 guideline dementia. [cited 2011 14.04]; Available from www.dgn.org/images/stories/dgn/leitlinien/ll-demenz/ll-demenz-lang-170210.pdf2008. [39] Bach JP, Ziegler U, Deuschl G, Dodel R, Doblhammer-Reiter G. Projected numbers of people with movement disorders in the years 2030 and 2050. Mov Disord 2011;26(12):228690 . 